\title{
Off-pump bilateral internal thoracic artery grafting in patients with left main disease
}

\author{
Toshihiro Fukui, MD, PhD, ${ }^{\mathrm{a}}$ Minoru Tabata, MD, MPH, ${ }^{\mathrm{a}}$ Susumu Manabe, $\mathrm{MD}, \mathrm{PhD},{ }^{\mathrm{a}}$ \\ Tomoki Shimokawa, MD, PhD, ${ }^{\mathrm{a}}$ Jun Shimizu, MD, PhD,${ }^{\mathrm{b}}$ Satoshi Morita, MD, $\mathrm{PhD},{ }^{\mathrm{c}}$ and \\ Shuichiro Takanashi, MD ${ }^{\text {a }}$
}

\begin{abstract}
Objective: This study assessed the safety and efficacy of off-pump bilateral internal thoracic artery grafting in patients with left main disease.

Methods: We reviewed the records of 768 patients who underwent off-pump bilateral internal thoracic artery grafting between September 2004 and June 2009. Bilateral internal thoracic artery grafts were used for the left coronary system in all patients, of whom 268 had left main disease and 500 did not. We compared operative and postoperative variables and early and 1-year angiographic patency rates of the bilateral internal thoracic artery between the 2 groups.
\end{abstract}

\begin{abstract}
Results: The perioperative mortality and incidence of postoperative complications were not significantly different between groups. In patients without left main disease, the left and right internal thoracic arteries were used for the left anterior descending artery in $87.4 \%$ and $12.2 \%$ of patients, respectively. In patients with left main disease, the left and right internal thoracic arteries were used for the left anterior descending artery in $70.5 \%$ and $29.1 \%$ of patients, respectively. In patients with left main disease, the patency rates for the left and right internal thoracic arteries at 1-year postoperative follow-up were $97.0 \%$ and $93.2 \%$, respectively. In patients without left main disease, the patency rates for the left and right internal thoracic arteries at 1-year follow-up were $97.6 \%$ and $91.6 \%$, respectively. The patency rates of the left and right internal thoracic arteries did not differ significantly in patients with or without left main disease $(P=.9803$ and $P=.7205$ in left and right internal thoracic arteries, respectively).
\end{abstract}

Conclusions: Off-pump bilateral internal thoracic artery grafting was safe and effective in patients with left main disease. The patency rates of both grafts were comparable to those of patients without left main disease. (J Thorac Cardiovasc Surg 2010;140:1040-5)

Coronary artery disease (CAD) with left main disease (LMD) has historically been considered to carry a higher operative risk in coronary artery bypass grafting $(\mathrm{CABG})$ than $\mathrm{CAD}$ without LMD. ${ }^{1,2}$ Recent advancement in operative techniques and perioperative management has enabled surgeons to perform CABG safely in patients with LMD. Generally, off-pump CABG is not preferred in patients with LMD because the displacement of the heart could cause torsion of LMD and acute hemodynamic deterioration. ${ }^{3}$ Some investigators have reported the safety of off-pump CABG in patients with LMD in studies with a relatively small sample size. ${ }^{4-7}$

Bilateral internal thoracic artery (ITA) grafting for revascularization has better survival benefits than single ITA

\footnotetext{
From the Departments of Cardiovascular Surgery ${ }^{\mathrm{a}}$ and Anesthesiology, ${ }^{\mathrm{b}}$ Sakakibara Heart Institute, Tokyo, Japan; and Department of Biostatistics and Epidemiology, Yokohama City University Medical Center, Yokohama, Japan.

Disclosures: None.

Received for publication Sept 17, 2009; revisions received Nov 2, 2009; accepted for publication Nov 27, 2009; available ahead of print March 2, 2010.

Address for reprints: Toshihiro Fukui, MD, PhD, Department of Cardiovascular Surgery, Sakakibara Heart Institute, 3-16-1 Asahi-cho, Fuchu City, Tokyo 183-0003, Japan (E-mail: tfukui-cvs@umin.ac.jp).

$0022-5223 / \$ 36.00$

Copyright (c) 2010 by The American Association for Thoracic Surgery doi:10.1016/j.jtcvs.2009.11.069
}

grafting, ${ }^{8}$ and patency rates and survival benefits are satisfactory when bilateral ITA grafts are used for the left coronary system. ${ }^{9}$ The combination of off-pump CABG with bilateral ITA grafting also yields favorable outcomes. ${ }^{10}$ However, the rate of bilateral ITA use is still low. ${ }^{11}$

The aims of the present study are to assess the safety and efficacy of off-pump bilateral ITA grafting in patients with LMD and to assess early and 1-year angiographic results of bilateral ITA grafts in these patients.

\section{PATIENTS AND METHODS \\ Patient Population}

Between September 2004 and June 2009, 930 patients underwent isolated CABG at Sakakibara Heart Institute. Of those, 884 patients $(95.1 \%$ of all isolated CABG cases) underwent isolated off-pump CABG and 768 patients $(86.9 \%$ of all isolated off-pump CABG cases) underwent offpump bilateral ITA grafting (Table 1). Table 2 shows the preoperative characteristics of these 768 patients, of whom 268 had LMD (LMD group) and 500 did not have LMD (non-LMD group). LMD was defined as the presence of $50 \%$ or greater stenosis in any angiographic view according to the Society of Thoracic Surgeons database.

\section{Operation}

General anesthesia was induced with midazolam $(0.2 \mathrm{mg} / \mathrm{kg})$ and fentanyl (4 $\mu \mathrm{g} / \mathrm{kg})$. Neuromuscular block was achieved with vecuronium 

Abbreviations and Acronyms
$\mathrm{CABG}=$ coronary artery bypass grafting
$\mathrm{CAD}=$ coronary artery disease
ITA $=$ internal thoracic artery
LAD $=$ left anterior descending
LMD = left main disease

TABLE 1. Distribution of patients undergoing isolated coronary artery bypass grafting

\begin{tabular}{lccr}
\hline & Single ITA & Bilateral ITA & Total \\
\hline On-pump CABG & 22 & 24 & 46 \\
Off-pump CABG & 116 & 768 & 884 \\
Total & 138 & 792 & 930 \\
\hline
\end{tabular}

$C A B G$, Coronary artery bypass grafting; ITA, internal thoracic artery.

Preoperative, intraoperative, postoperative, and angiographic variables were compared in patients with LMD and without LMD. The institutional review board approved this retrospective study and waived the need for written consents.

Nonelective operations included both emergency and urgent cases according to the definition of the Society of Thoracic Surgeons database. Operative death was defined as death occurring within 30 days after surgery. Low-output syndrome was defined as the postoperative need for any dose of adrenaline or more than $5 \mu \mathrm{g} / \mathrm{kg}^{-1} / \mathrm{min}^{-1}$ of dopamine or dobutamine. Perioperative myocardial infarction was defined as a positive result for new $\mathrm{Q}$ waves in an electrocardiogram or a peak creatine kinase MB level of greater than $10 \%$ of total creatine kinase. Respiratory failure was defined as requiring prolonged ventilation ( $>48$ hours) or having pneumonia. A postoperative cerebrovascular accident was defined as having a new stroke or intracranial bleeding confirmed by computed tomography. In patients with preoperative stroke, postoperative stroke was defined as a worsening of the neurologic deficit with new radiologic findings.

Patent graft was defined as a graft without occlusion, significant stenosis $(>90 \%)$, or string sign. String sign was defined as luminal narrowing throughout the entire conduit, including stenosis of $90 \%$ or greater.

Early and 1-year patency rates were calculated by dividing the number of patent grafts by the total number of grafts. If patients with early nonpatent grafts underwent a 1-year angiogram, those nonpatent grafts were also counted as 1-year nonpatent grafts.

\section{Statistical Analysis}

All statistical analyses were performed using StatView 5.0 software (SAS Institute Inc, Cary, NC). Continuous variables are reported as the mean \pm standard deviation if they are normally distributed. Otherwise, they are reported as a median. Continuous variables were compared by the Student $t$ test, and discrete variables were compared by the chi-square test or Fisher's exact test. Actuarial event-free survival curves were estimated by the Kaplan-Meier method. The log-rank test was used to assess whether there was a difference in survival between subject groups.

\section{RESULTS \\ Clinical Outcomes}

Preoperative characteristics of both groups are shown in Table 2. Patients with LMD were older than those without LMD $(P=$.0226). The rate of unstable angina $(P=.0010)$ and the mean Canadian Cardiovascular Society class $(P=.0079)$ were higher in patients with LMD than in those without LMD. The mean number of diseased vessels was larger in patients without LMD than in those with LMD $(P=.0117)$. Preoperative ejection fraction $(P=$ $.0492)$ and creatinine levels $(P=.0318)$ were significantly better in patients with LMD than in those without LMD. More patients without LMD had a history of congestive heart failure $(P=.0359)$, prior myocardial infarction $(P=$ $.0002)$, previous stroke $(P=.0326)$, and diabetes mellitus $(P=.0281)$ than those with LMD. More patients with

\section{Angiography}

Early postoperative angiography was performed in 615 patients $(80.1 \%)$ operative angiography was 10 days after surgery (range 1-20 days). If paangiography was performed at that time. Unless patients became symptomatic within 1 year after surgery, a follow-up angiography was performed at 1 year after surgery. Follow-up postoperative angiography was performed in 381 patients $(49.6 \%)$, and the median time was 12.2 months after surgery (range 2-21 months). Of these patients, 352 (45.8\%) underwent both early and 1-year angiographic studies. 
TABLE 2. Preoperative variables

\begin{tabular}{|c|c|c|c|c|}
\hline & All & LMD group & Non-LMD group & $P$ value \\
\hline No. & 768 & 268 & 500 & \\
\hline Age, y & $68.0 \pm 9.5$ & $69.1 \pm 9.7$ & $67.4 \pm 9.3$ & .0226 \\
\hline Gender, female & $141(18.4 \%)$ & $56(20.9 \%)$ & $85(17.0 \%)$ & .2182 \\
\hline Body surface area $\left(\mathrm{m}^{2}\right)$ & $1.7 \pm 0.2$ & $1.7 \pm 0.2$ & $1.7 \pm 0.2$ & .6108 \\
\hline Unstable angina & $239(31.1 \%)$ & $104(38.8 \%)$ & $135(27.0 \%)$ & .0010 \\
\hline $\mathrm{CCS}$ & $2.3 \pm 0.9$ & $2.4 \pm 0.9$ & $2.2 \pm 0.9$ & .0079 \\
\hline Ejection fraction $(\%)$ & $56.1 \pm 11.8$ & $57.3 \pm 11.3$ & $55.5 \pm 12.0$ & .0492 \\
\hline Diseased vessels & $2.8 \pm 0.4$ & $2.8 \pm 0.4$ & $2.8 \pm 0.4$ & .0117 \\
\hline Previous PCI & $222(28.9 \%)$ & $74(27.6 \%)$ & $148(29.6 \%)$ & .6165 \\
\hline Congestive heart failure & $103(13.4 \%)$ & $26(9.7 \%)$ & $77(15.4 \%)$ & .0359 \\
\hline Prior myocardial infarction & $363(47.3 \%)$ & $102(38.1 \%)$ & $261(52.2 \%)$ & .0002 \\
\hline Hypertension & $513(66.8 \%)$ & $174(64.9 \%)$ & $339(67.8 \%)$ & .4679 \\
\hline Diabetes mellitus & $361(47.0 \%)$ & $111(41.4 \%)$ & $250(50.0 \%)$ & .0281 \\
\hline Insulin & $79(10.3 \%)$ & $13(4.9 \%)$ & $66(13.2 \%)$ & .0005 \\
\hline Hyperlipidemia & $470(61.2 \%)$ & $172(64.2 \%)$ & $298(59.6 \%)$ & .2446 \\
\hline Smoking & $461(60.0 \%)$ & $156(58.2 \%)$ & $305(61.0 \%)$ & .4995 \\
\hline Previous stroke & $95(12.4 \%)$ & $24(9.0 \%)$ & $71(14.2 \%)$ & .0326 \\
\hline Peripheral vascular disease & $68(8.9 \%)$ & $21(7.8 \%)$ & $47(9.4 \%)$ & .5525 \\
\hline Creatinine $(\mathrm{mg} / \mathrm{dL})$ & $1.2 \pm 1.3$ & $1.0 \pm 0.8$ & $1.2 \pm 1.6$ & .0318 \\
\hline COPD & $31(4.0 \%)$ & $9(3.4 \%)$ & $22(4.4 \%)$ & .6122 \\
\hline Nonelective & $93(12.1 \%)$ & $54(20.1 \%)$ & $39(7.8 \%)$ & $<.0001$ \\
\hline Preoperative IABP use & $46(6.0 \%)$ & $29(10.8 \%)$ & $17(3.4 \%)$ & $<.0001$ \\
\hline Redo & $6(0.8 \%)$ & $2(0.7 \%)$ & $4(0.8 \%)$ & $>.9999$ \\
\hline
\end{tabular}

CCS, Canadian Cardiovascular Society; COPD, chronic obstructive pulmonary disease; IABP, intraaortic balloon pump; $L M D$, left main disease; $P C I$, percutaneous coronary intervention.

LMD had emergency or urgent operations $(P<.0001)$ and preoperative use of intraaortic balloon pump $(P<.0001)$ than those without LMD.

Target coronary artery vessels of left and right ITA grafts are shown in Table 3. In patients with LMD, the right ITA was used as an in situ graft in 207 patients $(77.2 \%)$ and as a free graft in 61 patients $(22.8 \%)$. In patients without LMD, the right ITA was used as an in situ graft in 375 patients $(75.0 \%)$ and as a free graft in 125 patients $(25.0 \%)$. There was no statistical difference between the 2 groups in the in situ rate of right ITA $(P=.5472)$.

In patients with LMD, left and right ITA grafts were used for the LAD in 189 patients $(70.5 \%)$ and 78 patients (29.1\%), respectively. In patients without LMD, left and right ITAs were used for the LAD in 437 patients $(87.4 \%)$ and 61 patients $(12.2 \%)$, respectively. The right ITA was used for the LAD more frequently in patients with LMD than in those without LMD $(P<.0001)$. This tendency was also found when the target of the right ITA was compared between patients with unstable angina and patients with stable angina. The right ITA was more frequently used for the LAD in patients with unstable angina than in patients with stable angina $(36.5 \%$ vs $24.4 \%, P=.046)$.

Operative and postoperative variables are listed in Table 4. Patients without LMD had a higher mean number of distal anastomoses per patient than those with LMD $(P=$ .0012). The rate of long segmental reconstruction of the
LAD was higher in patients without LMD than in those with LMD $(P<.0001)$. Patients without LMD had significantly longer operation times than those with LMD $(P<$ $.0001)$. The transfusion rate was significantly higher in patients with LMD than in those without LMD $(P=.0393)$. The operative mortality and incidence of postoperative complications were not significantly different between the 2 groups.

During the follow-up period, 1 patient died of heart failure, 2 patients had recurrent angina, 4 patients had congestive heart failure, and 1 patient had a stroke in the group with LMD. Freedom from death and other cardiac or cerebrovascular events was $96.5 \% \pm 1.2 \%$ at 3 years. One patient died of heart failure, 3 patients had recurrent angina, and 9 patients had congestive heart failure in the group without LMD. Freedom from death and other cardiac or cerebrovascular events was $96.3 \% \pm 0.9 \%$ at 3 years. There was no significant difference between the groups regarding event-free rate $(P=.8603)$.

\section{Angiographic Outcomes}

Early and 1-year postoperative angiograms were performed in 615 patients $(80.1 \%)$ and 381 patients $(49.6 \%)$, respectively. Table 5 lists the patency rates of the left and right ITAs at both early and 1-year angiographic studies.

In patients with LMD, the patency rates of the ITA grafts were $98.6 \%$ (left ITA) and $98.6 \%$ (right ITA) at early 
TABLE 3. Targets of left and right internal thoracic artery grafts

\begin{tabular}{|c|c|c|c|}
\hline & $\begin{array}{l}\text { Left internal } \\
\text { thoracic artery }\end{array}$ & $\begin{array}{l}\text { Right internal } \\
\text { thoracic artery }\end{array}$ & No. \\
\hline \multirow[t]{7}{*}{ LMD group $(n=268)$} & LAD & Diagonal branch & $89(33.2 \%)$ \\
\hline & LAD & Circumflex artery & $95(35.4 \%)$ \\
\hline & LAD & Inflow of other graft & $5(1.9 \%)$ \\
\hline & Diagonal branch & LAD & $8(3.0 \%)$ \\
\hline & Diagonal branch & Circumflex artery & $1(0.3 \%)$ \\
\hline & Circumflex artery & LAD & $66(24.6 \%)$ \\
\hline & Inflow of other graft & LAD & $4(1.4 \%)$ \\
\hline \multirow[t]{8}{*}{ Non-LMD group $(\mathrm{n}=500)$} & LAD & Diagonal branch & $202(40.4 \%)$ \\
\hline & LAD & Circumflex artery & $211(42.2 \%)$ \\
\hline & LAD & Inflow of other graft & $24(4.8 \%)$ \\
\hline & Diagonal branch & LAD & $5(1 \%)$ \\
\hline & Diagonal branch & Circumflex artery & $1(0.2 \%)$ \\
\hline & Circumflex artery & LAD & $49(9.8 \%)$ \\
\hline & Circumflex artery & Diagonal branch & $1(0.2 \%)$ \\
\hline & Inflow of other graft & LAD & $7(1.4 \%)$ \\
\hline
\end{tabular}

$L A D$, Left anterior descending artery; $L M D$, left main disease.

angiography and $97.0 \%$ (left ITA) and $93.2 \%$ (right ITA) at 1 -year angiography. There were no significant differences in early $(P>.9999)$ and 1 -year $(P=.2547)$ patency rates between the left and the right ITAs.

In patients without LMD, the patency rates of the ITA grafts were $99.0 \%$ (left ITA) and $99.3 \%$ (right ITA) at early angiography and $97.6 \%$ (left ITA) and $91.6 \%$ (right ITA) at 1 -year angiography. Although there was no significant difference in the early patency rate $(P>.9999)$ between the left and the right ITAs, there was a significant difference in the 1-year patency rate $(P=.0056)$.

When patency rates of the left ITA were compared in patients with and without LMD, there were no significant differences in early $(P=.6999)$ or 1-year $(P=.9803)$ patency rates between the 2 groups. When the patency rates of the right ITA were compared in patients with and without LMD, there were no significant differences in early $(P=.4264)$ or 1 -year $(P=.7205)$ patency rates between the 2 groups.

\section{DISCUSSION}

The present study demonstrates the safety and efficacy of off-pump bilateral ITA grafting in patients with LMD. Furthermore, this study showed good early and 1-year patency rates of bilateral ITA grafts in this patient group.

The current gold standard of care for LMD is CABG. The American College of Cardiology/American Heart Association guidelines recognize only $\mathrm{CABG}$ as having a class IA indication for treatment of LMD. ${ }^{14,15}$ The evolution of surgical techniques and perioperative management has improved surgical outcomes. Percutaneous coronary intervention procedures recently have been performed for LMD and reported to have comparable results with

TABLE 4. Operative and postoperative data

\begin{tabular}{|c|c|c|c|c|}
\hline & All & LMD group & Non-LMD group & $P$ valu \\
\hline Anastomoses/patient & $4.2 \pm 1.2$ & $4.0 \pm 1.2$ & $4.3 \pm 1.1$ & .0012 \\
\hline Long segment reconstruction of LAD & $309(40.2 \%)$ & $77(28.7 \%)$ & $232(46.4 \%)$ & $<.0001$ \\
\hline Operation time (min) & $279.5 \pm 56.9$ & $268.2 \pm 56.8$ & $285.5 \pm 56.1$ & $<.0001$ \\
\hline Transfusion & $268(34.9 \%)$ & $107(39.9 \%)$ & $161(32.2 \%)$ & .0393 \\
\hline Intubation (h) & $9.6 \pm 14.8$ & $10.0 \pm 10.2$ & $9.5 \pm 16.8$ & .6485 \\
\hline Intensive care unit stay (d) & $1.9 \pm 7.8$ & $2.6 \pm 13.0$ & $1.5 \pm 1.8$ & .0598 \\
\hline Operative death (within $30 \mathrm{~d}$ ) & $7(0.9 \%)$ & $2(0.7 \%)$ & $5(1.0 \%)$ & $>.9999$ \\
\hline Reexploration because of bleeding & $6(0.8 \%)$ & $1(0.4 \%)$ & $5(1.0 \%)$ & .6706 \\
\hline Low output syndrome & $10(1.3 \%)$ & $6(2.2 \%)$ & $4(0.8 \%)$ & .1055 \\
\hline Perioperative myocardial infarction & $11(1.4 \%)$ & $4(1.5 \%)$ & $7(1.4 \%)$ & $>.9999$ \\
\hline Severe ventricular arrhythmia & $6(0.8 \%)$ & 0 & $6(1.2 \%)$ & .0969 \\
\hline Atrial fibrillation & $191(24.9 \%)$ & $66(24.6 \%)$ & $125(25.0 \%)$ & .9789 \\
\hline Required hemodialysis & $13(1.7 \%)$ & $7(2.6 \%)$ & $6(1.2 \%)$ & .2492 \\
\hline Stroke & $10(1.3 \%)$ & $3(1.1 \%)$ & $7(1.4 \%)$ & $>.9999$ \\
\hline Mediastinitis & $10(1.3 \%)$ & $3(1.1 \%)$ & $7(1.4 \%)$ & $>.9999$ \\
\hline
\end{tabular}

ITA, Internal thoracic artery; $L A D$, left anterior descending artery; $L M D$, left main disease. 
TABLE 5. Cumulative angiographic patency rates of left and right internal thoracic artery grafts

\begin{tabular}{llc}
\hline & Early $(\mathbf{n}=\mathbf{6 1 5})$ & $\mathbf{1} \mathbf{y}(\mathbf{n}=\mathbf{3 8 1})$ \\
\hline Total & $98.9 \%(1217 / 1230)$ & $94.8 \%(722 / 762)$ \\
LMD group & $98.6 \%(424 / 430)$ & $95.1 \%(251 / 264)$ \\
$\quad$ Left internal thoracic artery & $98.6 \%(212 / 215)$ & $97.0 \%(128 / 132)$ \\
Right internal thoracic artery & $98.6 \%(212 / 215)$ & $93.2 \%(123 / 132)$ \\
Non-LMD group & $99.1 \%(793 / 800)$ & $94.6 \%(471 / 498)$ \\
Left internal thoracic artery & $99.0 \%(396 / 400)$ & $97.6 \%(243 / 249)$ \\
Right internal thoracic artery & $99.3 \%(397 / 400)$ & $91.6 \%(228 / 249)$ \\
\hline
\end{tabular}

$L M D$, Left main disease.

$\mathrm{CABG} ;{ }^{16}$ however, long-term results have not been reported. A meta-analysis of LMD also supports the superiority of CABG over percutaneous coronary intervention in revascularization of LMD; the study showed that repeated revascularization was less frequent after CABG than after percutaneous coronary intervention. ${ }^{17}$ Generally, off-pump CABG is not preferred in patients with LMD because displacement of the heart could induce hemodynamic deterioration. ${ }^{3}$ On the other hand, several studies have shown the safety and feasibility of off-pump CABG in patients with LMD. $^{4-7}$ Dewey and colleagues ${ }^{6}$ reported that the use of cardiopulmonary bypass is an independent risk factor for death in patients with LMD, with an odds ratio of 7.3 (95\% confidence interval, 1.3-138.4). Thomas and colleagues ${ }^{7}$ reported that off-pump CABG was safely performed in patients with and without LMD. They speculated that the favorable outcomes after off-pump CABG were achieved because of the improved myocardial preservation, reduced reperfusion injury, and absence of the hypothermic insult. Even in those series, bilateral ITA grafting was infrequently performed.

Several institutions have reported that bilateral ITA grafting results in better survival and greater freedom from reintervention than single ITA grafting. ${ }^{18,19}$ However, the American College of Cardiology/American Heart Association guidelines still do not recommend the use of bilateral ITA grafting because there are insufficient data for detailed analysis. ${ }^{14}$ Bilateral ITA grafting has not become a routine strategy, even in elective patients, for multiple reasons, including increased operative difficulty, increased operating times, and risk of wound complications. ${ }^{14}$ There are only a few reports regarding myocardial revascularization with bilateral ITA grafting in patients with $\mathrm{LMD} .{ }^{20} \mathrm{We}$ have routinely used bilateral ITA grafts for CABG when feasible even in high-risk patients with LMD. There are various grafting strategies with bilateral ITA grafts. Although our first choice is the left ITA for the LAD, we use the right ITA for the LAD more frequently in those with LMD than in those without LMD. Patients with unstable hemodynamics cannot tolerate torsion of the left main trunk because of the circumflex position without LAD grafting. In those patients, we graft the LAD with the right ITA and then graft the circumflex territory with the left ITA. The left ITA to the LAD would suffer from increased physical tension when the heart is pulled toward the right during the anastomosis of the circumflex territory. However, in patients with stable hemodynamics, revascularization of the LAD was performed with the left ITA as usual.

The present study used intraaortic balloon counterpulsation in a higher proportion of patients with LMD than in patients without LMD. Suzuki and colleagues ${ }^{21}$ demonstrated that using an intraaortic balloon pump during off-pump CABG was effective in high-risk patients. They comment that the effects of intraaortic balloon pump support, such as the reduction of ventricular afterload, improvement of diastolic coronary perfusion, and enhancement of subendocardial perfusion, are beneficial to the displaced heart in maintaining hemodynamic stability during off-pump CABG. These benefits may have influenced the favorable results after off-pump CABG in our study. In the present study, all intraaortic balloon pumps were placed preoperatively. We believe that insertion of an intraaortic balloon pump should not be delayed in hemodynamically unstable patients with LMD.

We have demonstrated that clinical and angiographic outcomes are not significantly different in patients with and without LMD at early and 1-year follow-ups. The 1-year patency rate of the right ITA graft was relatively low in patients without LMD. However, there was no significant difference in the patency rates of the right ITA grafts in patients with or without LMD.

We used the ITA as a skeletonized graft. A skeletonized ITA provides a longer length and better flexibility than a pedicled ITA. Skeletonization ensures that the right ITA reaches the posterolateral vessels through the transverse sinus as an in situ graft. Furthermore, multiple sequential grafting can be performed easily with a skeletonized free right ITA. With the skeletonization technique, using bilateral ITAs may no longer be a risk factor for mediastinitis because the collateral blood supply to the sternum is preserved. ${ }^{22}$ In the present study, the overall mediastinitis rate of $1.3 \%$ is not particularly high; however, the best practice in the literature is approximately $0.3 \% .{ }^{23}$ At Sakakibara Heart Insitute, the mediastinitis rate in patients undergoing non-bilateral ITA grafting was $0 \%(0 / 116)$. However, there was no difference regarding the mediastinitis rate between patients with bilateral ITA and patients with non-bilateral ITA $(P=.3756)$.

\section{Study Limitations}

Our study has the following limitations. It is a retrospective observational study, not a randomized controlled trial. We did not compare off-pump CABG with bilateral ITAs with other types of CABG (single ITA grafting or conventional on-pump CABG) in patients with LMD; however, at least we showed that our routine off-pump CABG with bilateral ITAs is safe and effective in patients with LMD. In addition, we did not follow up all patients with bilateral ITA 
grafts. Our findings may not be applicable to patient groups who did not have a follow-up angiogram, namely, the elderly and patients with renal insufficiency.

\section{CONCLUSIONS}

Off-pump bilateral ITA grafting in patients with LMD can be performed safely with acceptable early and 1-year patency rates.

\section{References}

1. Baur HR, Peterson TA, Arnar O, Gannon PG, Gobel FL. Predictors of perioperative myocardial infarction in coronary artery operation. Ann Thorac Surg. 1981; 31:36-44.

2. Chaitman BR, Rogers WJ, Davis K, Tyras DH, Berger R, Bourassa MG, et al. Operative risk factors in patients with left main coronary-artery disease. $N$ Engl $J$ Med. 1980;303:953-7.

3. Watters MP, Ascione R, Ryder IG, Ciulli F, Pitsis AA, Angelini GD. Haemodynamic changes during beating heart coronary surgery with the 'Bristol Technique'. Eur J Cardiothorac Surg. 2001;19:34-40.

4. Yeatman M, Caputo M, Ascione R, Ciulli F, Angelini GD. Off-pump coronary artery bypass surgery for critical left main stem disease: safety, efficacy and outcome. Eur J Cardiothorac Surg. 2001;19:239-44.

5. Mannam G, Sajja LR, Dandu SB, Pathuri SN, Saikiran KV, Sompalli S. Off-pump coronary revascularization for left main coronary artery stenosis. Asian Cardiovasc Thorac Ann. 2008;16:473-8.

6. Dewey TM, Magee MJ, Edgerton JR, Mathison M, Tennison D, Mack MJ. Offpump bypass grafting is safe in patients with left main coronary disease. Ann Thorac Surg. 2001;72:788-91.

7. Thomas GN, Martinez EC, Woitek F, Emmert MY, Sakaguchi H, Muecke S, et al. Off-pump coronary bypass grafting is safe and efficient in patients with left main disease and higher EuroScore. Eur J Cardiothorac Surg. 2009;36:616-20.

8. Taggart DP, D'Amico R, Altman DG. Effect of arterial revascularization on survival: a systematic review of studies comparing bilateral and single internal mammary arteries. Lancet. 2001;358:870-5.

9. Cameron A, Davis KB, Green G, Schaff HV. Coronary bypass surgery with internal-thoracic-artery grafts-effects on survival over a 15-year period. $N$ Engl $J$ Med. 1996;334:216-9.

10. Kim KB, Cho KR, Chang WI, Lim C, Ham BM, Kim YL. Bilateral skeletonized internal thoracic artery graftings in off-pump coronary artery bypass: early result of Y versus in situ grafts. Ann Thorac Surg. 2002;74:S1371-6.
11. Tabata M, Grab JD, Khalpey Z, Edwards FH, O’Brien SM, Cohn LH, et al. Prevalence and variability of internal mammary artery graft use in contemporary multivessel coronary artery bypass graft surgery: analysis of the Society of Thoracic Surgeons National Cardiac Database. Circulation. 2009;120:935-40.

12. Fukui T, Takanashi S, Hosoda Y, Suehiro S. Early and midterm results of offpump coronary artery bypass grafting. Ann Thorac Surg. 2007;83:115-9.

13. Fukui T, Takanashi S, Hosoda Y. Long segmental reconstruction of diffusely diseased left anterior descending coronary artery with left internal thoracic artery with or without endarterectomy. Ann Thorac Surg. 2005;80:2098-105.

14. Eagle KA, Guyton RA, Davidoff R, Edwards FH, Ewy GA, Gardner TJ, et al., American College of Cardiology; American Heart Association. ACC/AHA 2004 guideline update for coronary artery bypass graft surgery: a report of the American College of Cardiology/American Heart Association Task Force on Practice Guidelines (Committee to Update the 1999 Guidelines for Coronary Artery Bypass Graft Surgery). Circulation. 2004;110:e340-437.

15. Smith CR. Surgery, not percutaneous revascularization, is the preferred strategy for patients with significant left main coronary stenosis. Circulation. 2009;119: 1013-20.

16. Teirstein PS. Percutaneous revascularization is the preferred strategy for patients with significant left main coronary stenosis. Circulation. 2009;119:1021-33.

17. Takagi H, Kawai N, Umemoto T. Stenting versus coronary artery bypass grafting for unprotected left main coronary artery disease: a meta-analysis of comparative studies. J Thorac Cardiovasc Surg. 2009;137:e54-7.

18. Lytle BW, Blackstone EH, Loop FD, Houghtaling PL, Arnold JH, Akhrass R, et al. Two internal thoracic artery grafts are better than one. J Thorac Cardiovasc Surg. 1999;117:855-72.

19. Endo M, Nishida H, Tomizawa Y, Kasanuki H. Benefit of bilateral over single internal mammary artery grafts for multiple coronary artery bypass grafting. $\mathrm{Circu}$ lation. 2001;104:2164-70.

20. Paolini G, Zuccari M, Di Credico G, Gallorini C, Stefano PL, Castiglioni A, et al Myocardial revascularization with bilateral internal thoracic artery in patients with left main disease: an incremental risk? Eur J Cardiothorac Surg. 1994;8: 576-9.

21. Suzuki T, Okabe M, Handa M, Yasuda F, Miyake Y. Usefulness of preoperative intraaortic balloon pump therapy during off-pump coronary artery bypass grafting in high-risk patients. Ann Thorac Surg. 2004;77:2056-9.

22. Higami T, Maruo A, Yamashita T, Shida T, Ogawa K. Histologic and physiologic evaluation of skeletonized internal thoracic artery harvesting with an ultrasonic scalpel. J Thorac Cardiovasc Surg. 2000;120:1142-7.

23. Rosmarakis ES, Prapas SN, Rellos K, Michalopoulos A, Samonis G, Falagas ME. Nosocomial infections after off-pump coronary artery bypass surgery: frequency, characteristics, and risk factors. Interact Cardiovasc Thorac Surg. 2007;6:759-67. 